\title{
Dissolved and atmospheric methane concentrations along a freshwater - seawater transect from the River Elbe into the North Sea
}

Bussmann, I., Brix, H., Kamjunke N., Ködel, U., Koschorreck, M., Schütze, C. 
Inland Elbe cruise, 4. - 12. Aug 2020

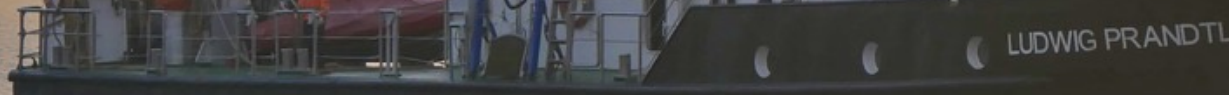

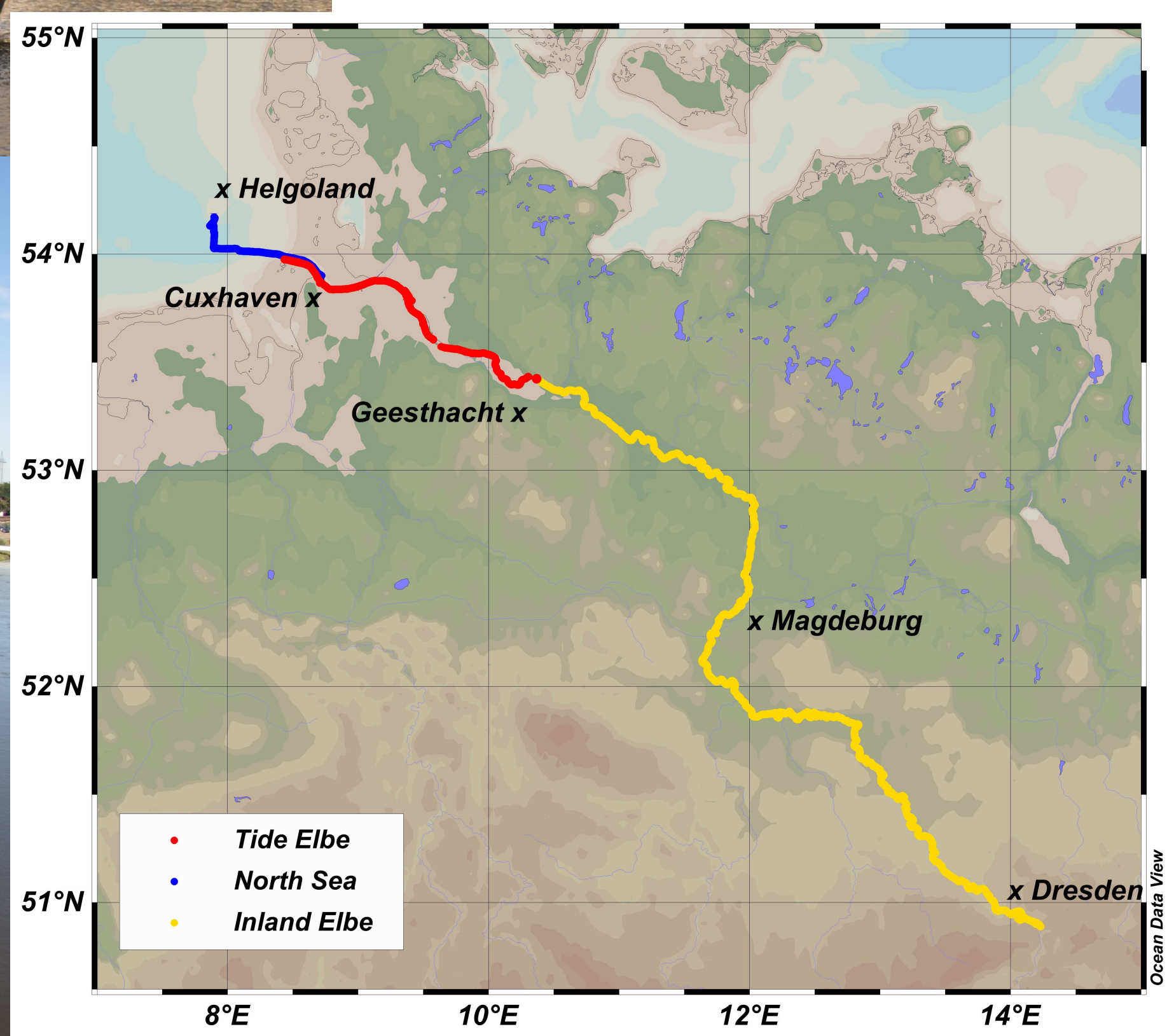




\section{Material \& Methods}

- Continuous, underway measurements of

- hydrographic parameters (Ferry Box)

- Dissolved $\mathrm{CH}_{4} \& \mathrm{CO}_{2}$ (Degasser + Greenhouse Gas Analyzer, LosGatos), Calibration with water samples analyzed with head space and GC)

- Atmospheric $\mathrm{CH}_{4} \& \mathrm{CO}_{2}$ (Licor)

- Discrete water samples for prim. production, chlorophyll, (see presentation vEGU-8721) 


\section{Questions}

- Focus on the Elbe river

- Influence of tributaries?

- Several hotspots, where and why?

- extension and influence of hotspots?

- Lagrangian sampling

- Does the dissolved $\mathrm{CH}_{4}$ influence the atmospheric $\mathrm{CH}_{4}$ ?

- Does the ratio of $\mathrm{CH}_{4} / \mathrm{CO}_{2}$ give more insights? 


\section{Overall Distribution of $\mathrm{CH}_{4}$}

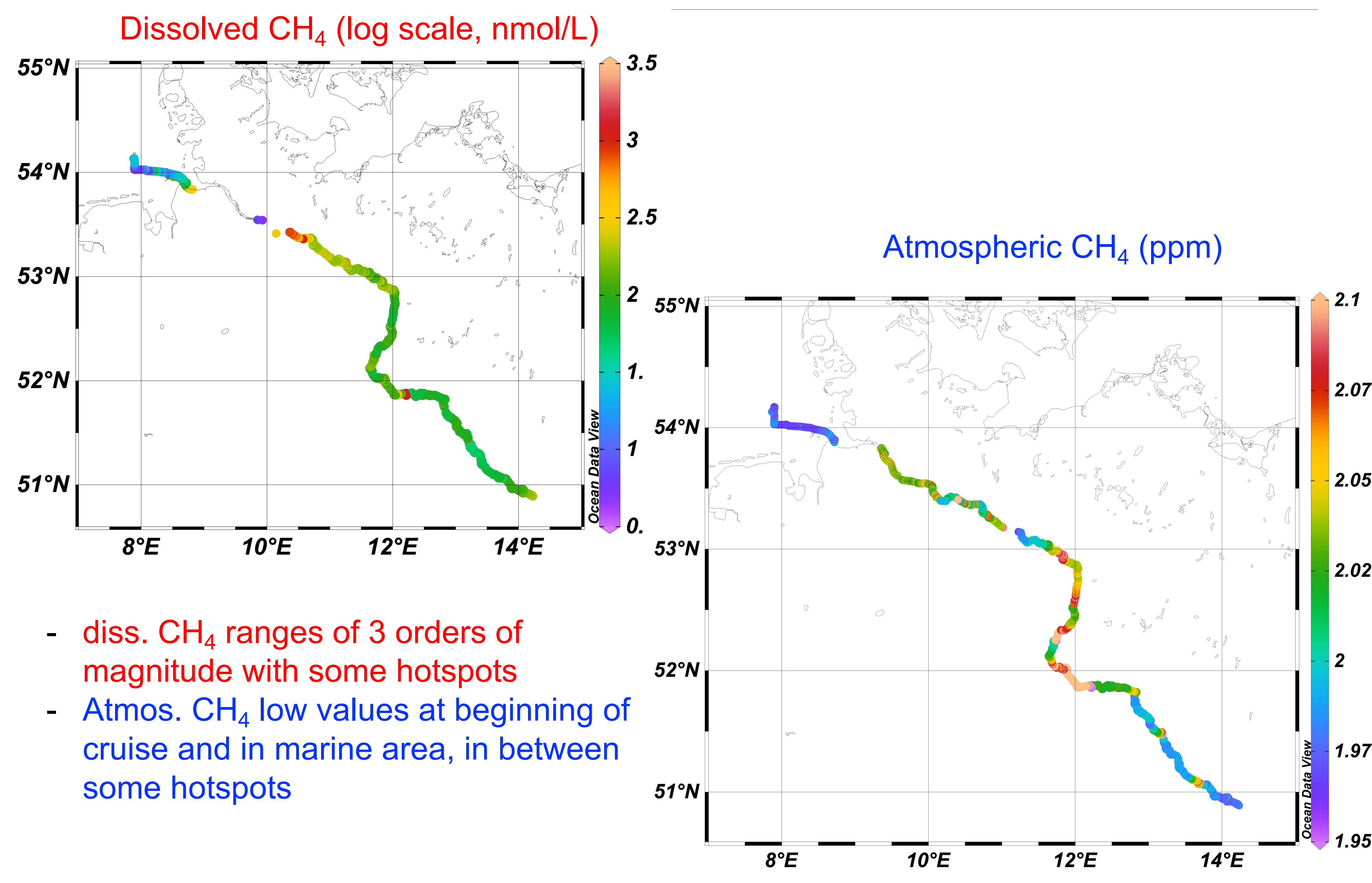




\section{Overall Distribution of $\mathrm{CH}_{4}$}

Dissolved $\mathrm{CH}_{4}$ (log scale, $\left.\mathrm{nmol} / \mathrm{L}\right)$

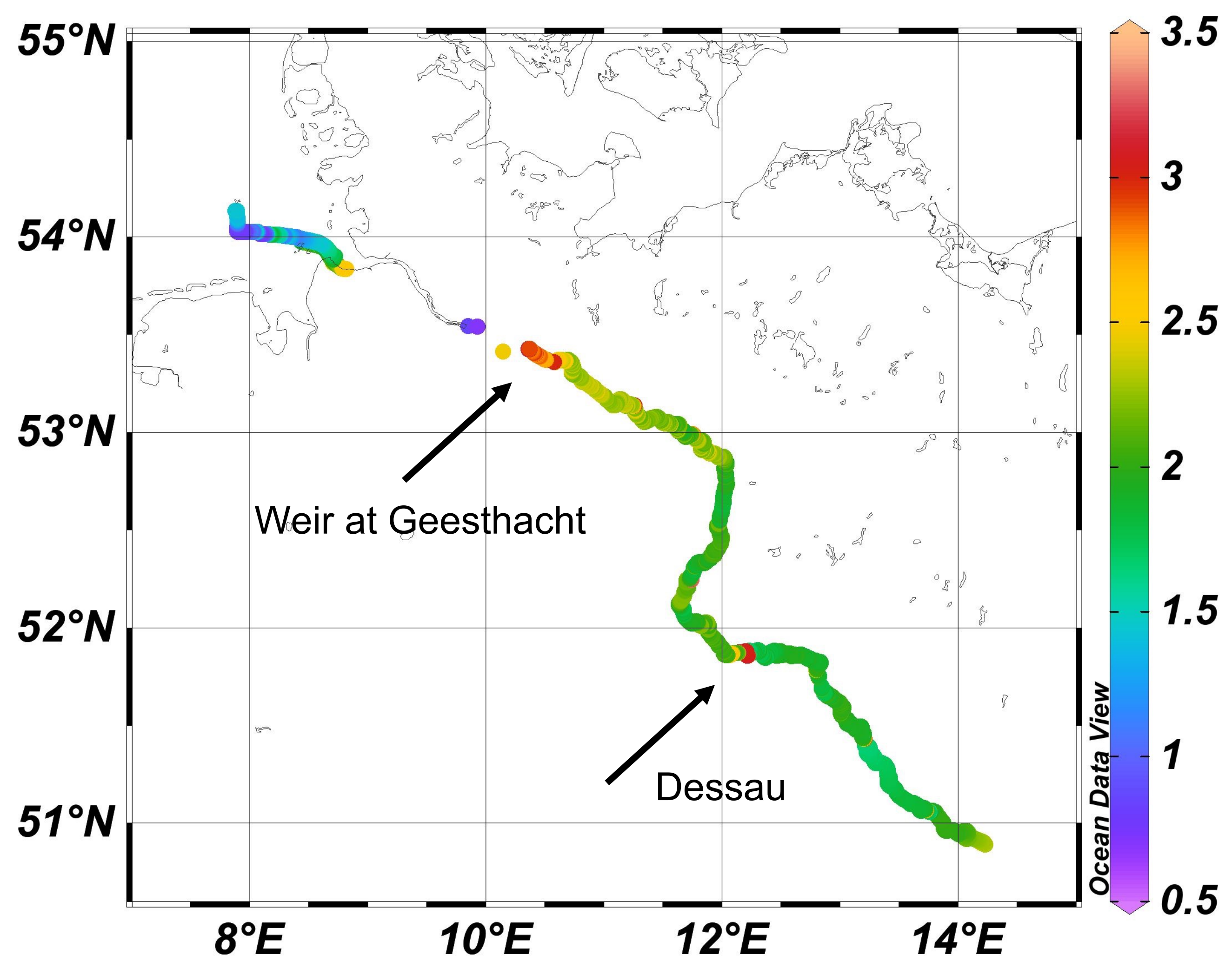




\section{Close up "near Dessau"}

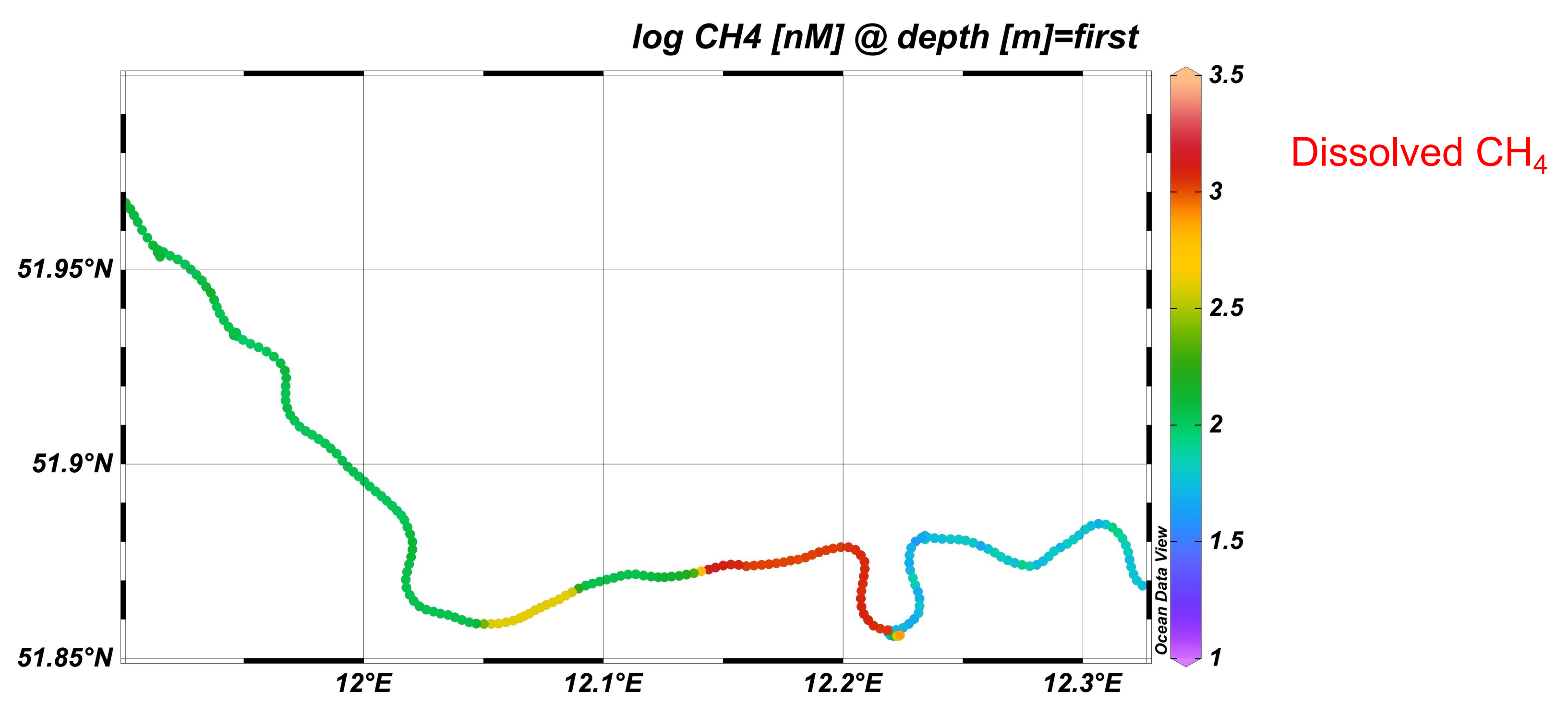

- Locally very steep increase of diss. \& atmos. $\mathrm{CH}_{4}$

- Hydrographic parameters (temp, cond, ph, $\mathrm{O}_{2}$, chl-a, turb) do not explain the $\mathrm{CH}_{4}$ increase

- Probably due to a lateral input of $\mathrm{CH}_{4}$-rich water from near by natural reserve area 


\section{Comparing diss. and atmos. $\mathrm{CH}_{4}$}

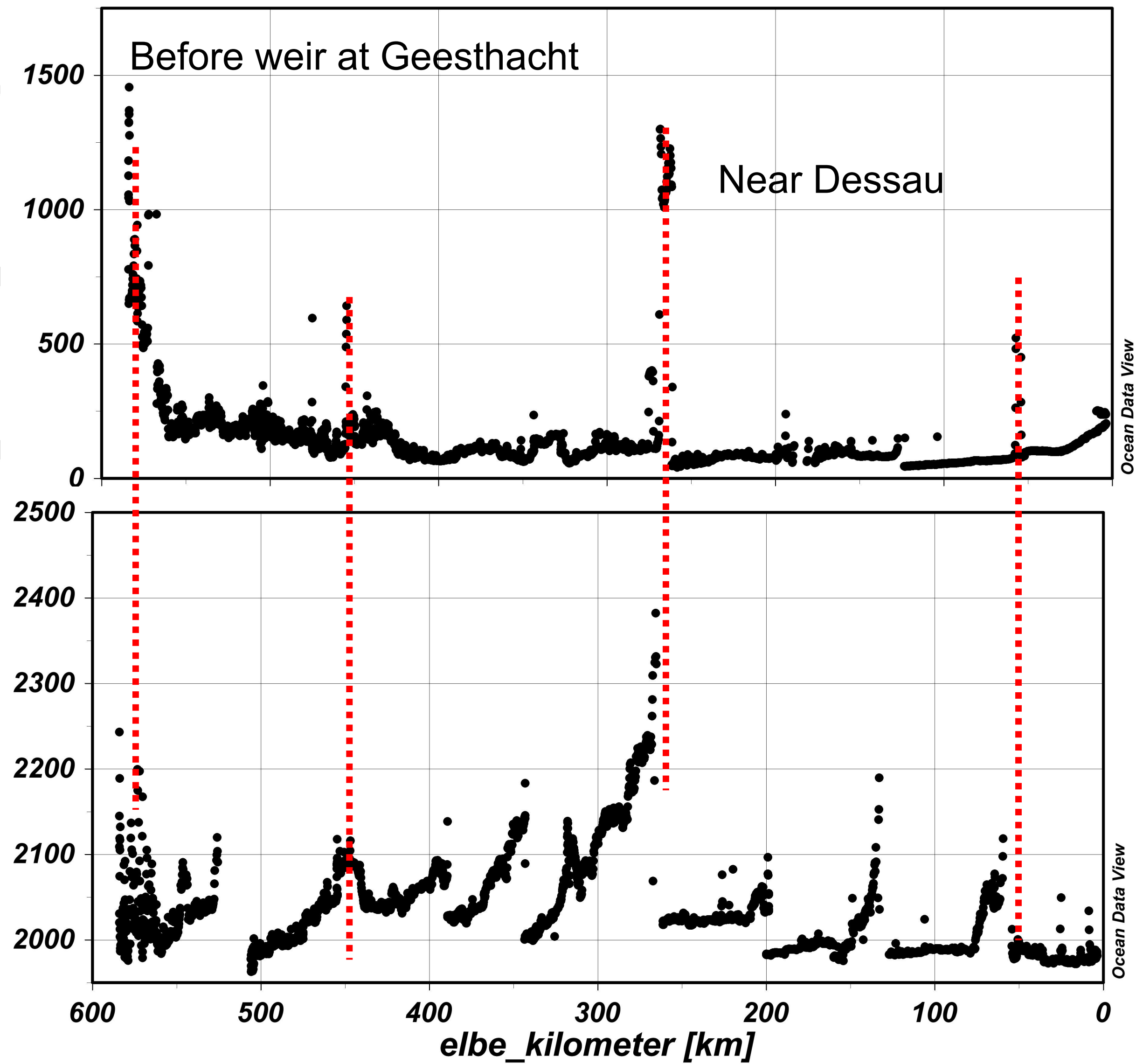

\section{Dissolved $\mathrm{CH}_{4}$}

- distinct pattern of atmosph. + diss. $\mathrm{CH}_{4}$

- Increase near Dessau for both

- Slight increase of atmosph. $\mathrm{CH}_{4}$ near the weir

Atmospheric $\mathrm{CH}_{4}$ 


\section{Diurnal pattern for atmos. $\mathrm{CH}_{4}$}

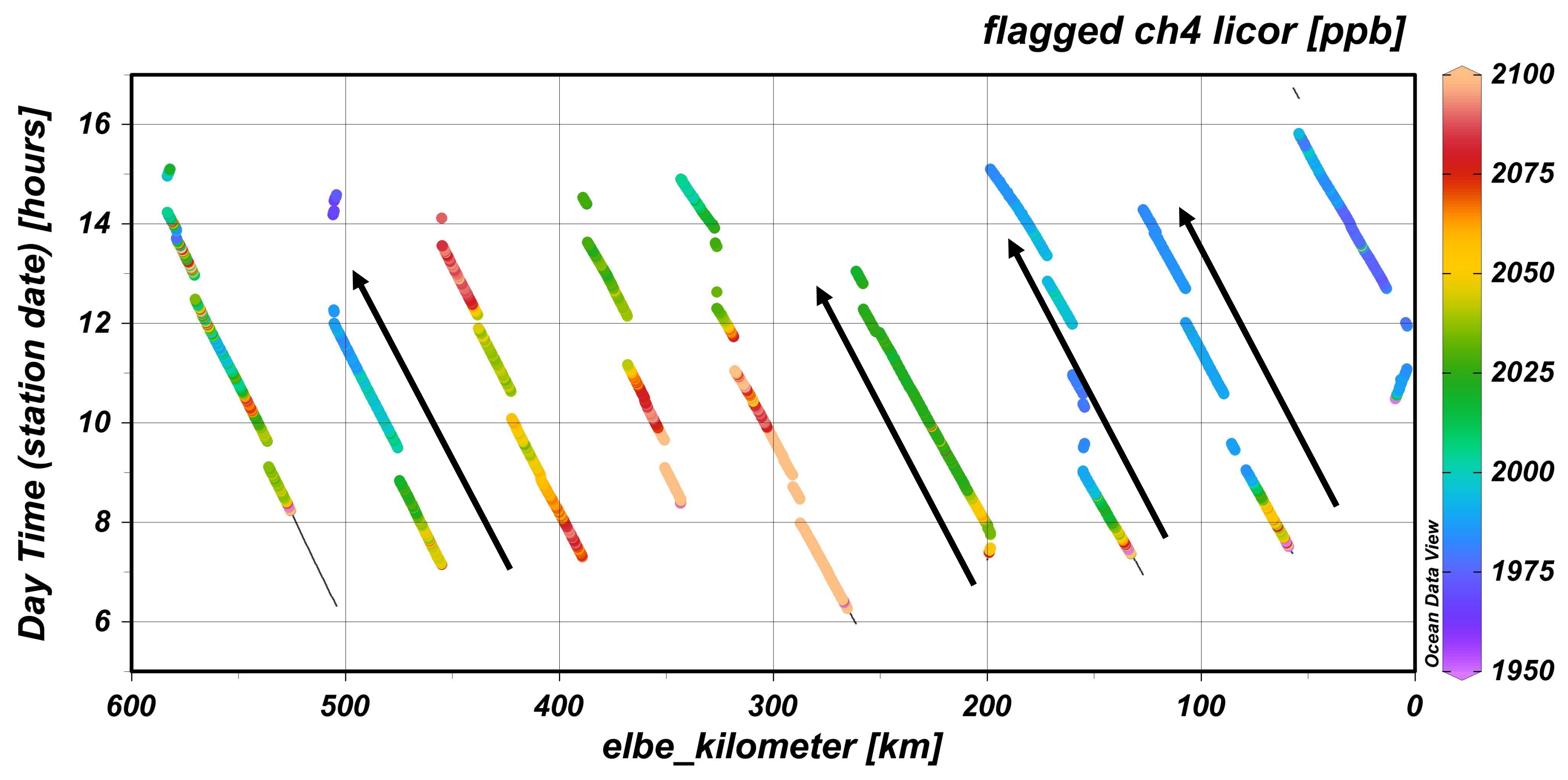

- Higher values in the morning, decreasing towards afternoon 


\section{Ratio of diss $\mathrm{CH}_{4} /$ diss $\mathrm{CO}_{2}$}

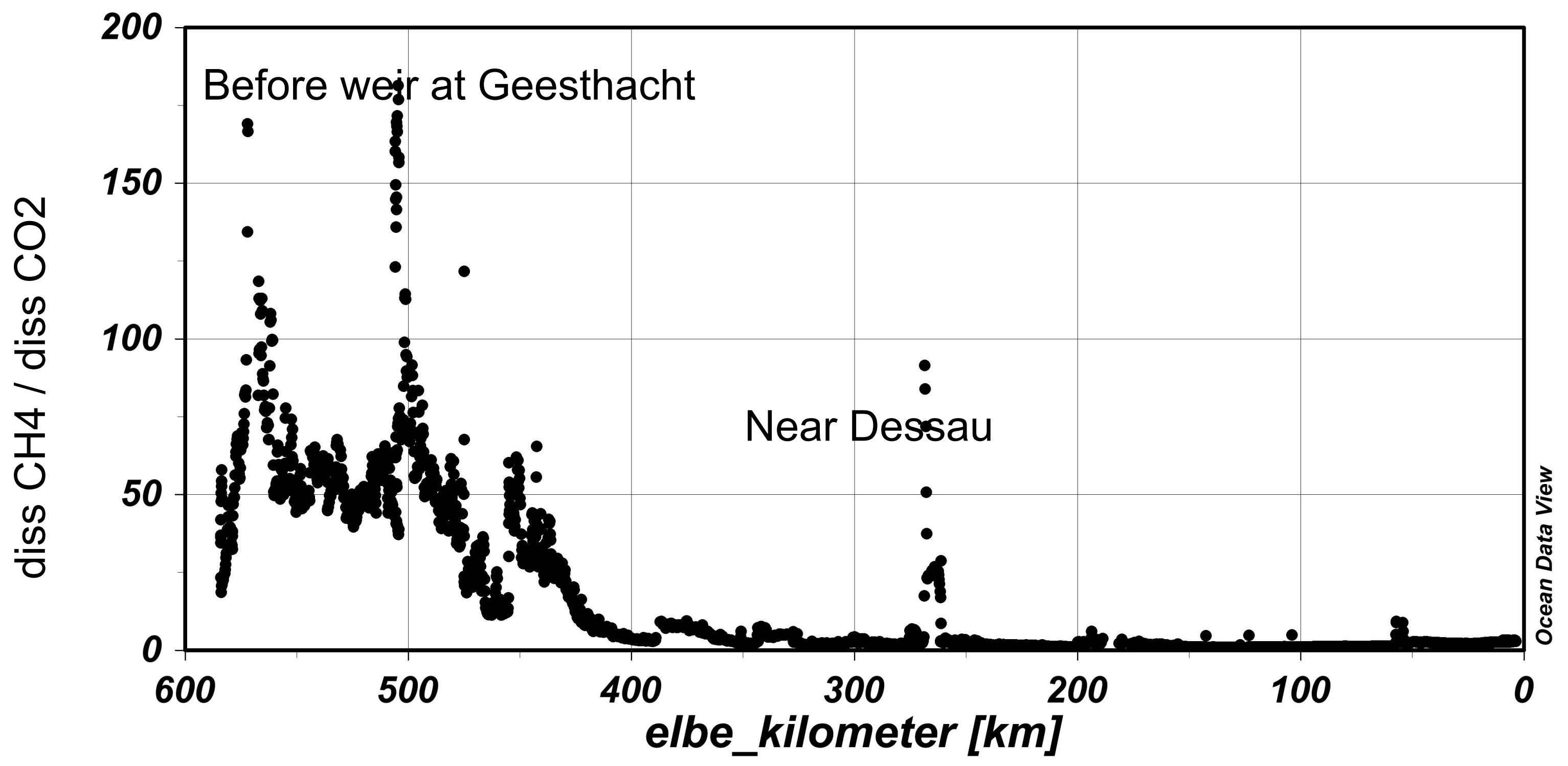

- Low ratios until km 400

- Clear peak near Dessau

- At km 500 ratio is influenced by $\mathrm{CO}_{2}$ decrease by increased primary production (previous presentation)

- Increase of ratio towards weir due to increase in $\mathrm{CH}_{4}$ 


\section{At the weir}

- High diss. $\mathrm{CH}_{4}$ correlates with

- $\uparrow$ diss. $\mathrm{CO}_{2}, \uparrow$ conductivity, $\uparrow$ turbidity, $\downarrow$ Chlorophyll, $\uparrow$ atmos. $\mathrm{CH}_{4}, \uparrow$ atmos. $\mathrm{CO}_{2}$

- Decrease in flow velocity

- => sedimentation of phytoplankton

- See also previous presentation, EGU21-8721

- => increase of atmos. + diss $\mathrm{CH}_{4}$

- => reduced gas transfer coefficient, may be ebullition 


\section{Influence of tributaries}

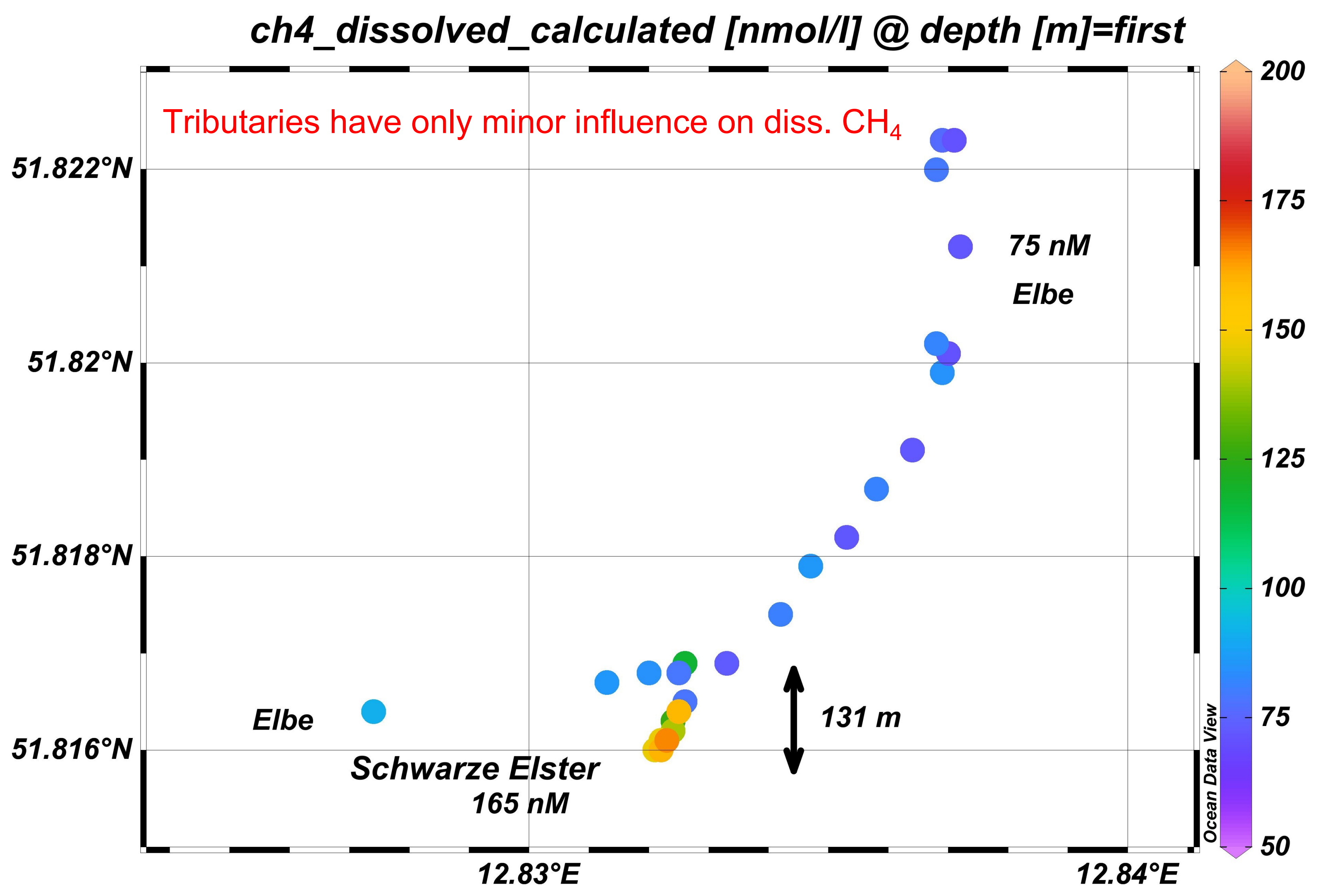




\section{Conclusions}

- We identified several hot spots for diss. $\mathrm{CH}_{4}$, which often are mirrored by atmospheric $\mathrm{CH}_{4}$ hotspots

- Reason for hotspots:

- Influence of primary production, flow velocities and not yet specified ones

- Spatial patterns of atmos. $\mathrm{CH}_{4}$ are overlain by diurnal patterns

- Tributaries have only minor influence on diss. $\mathrm{CH}_{4}$, within $100 \mathrm{~m}$, increased concentrations return to background values

Thank you for your attention! 